\title{
Recent population expansion and connectivity in the hydrothermal shrimp Rimicaris exoculata along the Mid-Atlantic Ridge
}

\author{
Sara Teixeira ${ }^{1,2}$, Marie-Anne Cambon-Bonavita ${ }^{3}$, Ester A. Serrão ${ }^{2}$, Daniel Desbruyéres ${ }^{1}$, \\ Sophie Arnaud-Haond ${ }^{1, *}$
}

\footnotetext{
${ }^{1}$ Ifremer - Centre de Brest, Departement "Etude des Ecosystèmes Profonds"- DEEP, BP 7029280 Plouzané Cedex, France

${ }^{2}$ Centre of Marine Sciences, CIMAR, University of Algarve, Campus of Gambelas, 8005-139 Faro, Portugal

${ }^{3}$ Ifremer Centre de Brest, Laboratoire de Microbiologie des Environnements Extrêmes, DEEP/LMEE, UMR 6197

UBO-CNRS-Ifremer, 29280 Plouzané, France
}

*: Corresponding author : Sophie Arnaud-Haond, email address : Sophie.Arnaud@ifremer.fr

\begin{abstract}
:
Aim Deep-sea hydrothermal vents are unstable habitats that are both spatially and temporally fragmented. In vent species, a 'short-term insurance' hypothesis would lead us to expect mostly selfrecruitment, limiting the loss of larvae in the deep ocean or water column and increasing genetic differentiation over the time elapsed since colonization. Alternatively, a 'long-term insurance' hypothesis would support the prediction of selection for large-scale dispersal, to ensure long-term persistence in these ephemeral habitats. The main goal of this study was to infer the spatial and temporal distribution of genetic diversity of the shrimp Rimicaris exoculata, which forms high-density local populations on hydrothermal vents along the Mid-Atlantic ridge.
\end{abstract}

Location Deep-sea hydrothermal vents along the Mid-Atlantic Ridge.

Methods We used sequences of mitochondrial cytochrome $c$ oxidase subunit I (COI, $710 \mathrm{bp}$ ) to assess the spatio-temporal distribution of genetic diversity across five hydrothermal fields from $36^{\circ} \mathrm{N}$ to $4^{\circ} \mathrm{S}$.

Results In contrast to previous results from pioneer studies, very high haplotype diversity was observed in vents across the entire region (i.e. 0.69-0.82), indicating current large effective population size and low drift. The star-like shape of the network of haplotypes, the lack of spatial genetic structure and the significance of tests reflecting demographic effects, together with the fitting of a population expansion model, all support a recent population expansion.

Main conclusions Our results suggest a very recent common history of $R$. exoculata populations/demes along the Mid-Atlantic Ridge, derived after a common bottleneck or founder event and followed by a concomitant demographic expansion. This study therefore suggests a large effective population size and/or high dispersal capacity, as well as a possible recent (re)colonization of MidAtlantic hydrothermal vents by $R$. exoculata.

Keywords : Bottleneck, deep sea biogeography, dispersal, genetic diversity, hydrothermal vents, marine biogeography, Mid-Atlantic Ridge, Rimicaris exoculata, spatio-temporal distribution. 


\section{Introduction}

Dispersal plays a central role in both the dynamics and evolution of species. Effective dispersal (i.e., gene flow) attenuates genetic differences among populations and increases the genetic variability within populations (Billiard \& Lenormand, 2005). Dispersal is a risky strategy as immigrants may never reach a suitable habitat, or face higher mortality and lower reproductive success in the receiver population (Ims \& Andreassen, 2000; Garant et al., 2007). Yet, dispersal can also offer clear advantages, particularly in fragmented ephemeral habitats, as it allows areas to be explored for more favourable habitats and extinction to be avoided by escaping locally deteriorating physical or biotic conditions, such as competition (Hamilton \& May, 1977; Olivieri et al., 1995). By enabling populations to randomly spread their progeny more evenly among different sites dispersal may indeed represent a favourable bet-hedging strategy in temporally variable or ephemeral ecosystems (Ronce \& Olivieri, 2004).

Deep-sea hydrothermal vents are an extreme example of a spatially and temporally unstable environment. Environments of this type are scattered worldwide along the global mid-ocean ridge system, and are sometimes thousands of kilometres apart (Tunnicliffe \& Fowler, 1996; Van Dover, 2000). They are extreme and unique habitats, with communities composed of specialized animals, dependent on chemoautotrophic microorganisms that exploit the reduced compounds (mainly $\mathrm{H}_{2} \mathrm{~S}$ and $\mathrm{CH}_{4}$ ) abundant in vent fluids (Desbruyères et al., 2000). Each hydrothermal vent has a characteristic profile that may differ in depth, temperature and/or chemical composition (Van Dover, 2000), adding abiotic heterogeneity to the spatial component of habitat fragmentation that potentially influences the patchy community distribution and limited effective dispersal. Besides the distance separating successive hydrothermal vents, communities may also become genetically isolated across transform faults, which act as potential barriers between populations and limit effective dispersal among sites (Plouviez et al., 2009). This hypothesis is supported by the high levels of endemism found across biogeographic provinces (Van Dover et al., 2002; Fabri et al., 2006; Bachraty et al., 2009; Moalic et al. submitted) as well as by the rather high genetic differentiation found across some neighbouring sites (e.g. Jollivet et al., 1999; Won et al., 2003; Hurtado et al., 2004; Matabos et al., 2008; Young et al., 2008; Plouviez et al., 2009), which indeed suggest a limited effective dispersal over large distances. On the other hand, depending on the sea floor geology and magmatic and tectonic events, individual hydrothermal vents have a relatively short lifespan of 1 to 100 years for fast spreading ridges such as the East Pacific Rise (Hessler et al., 1988; Lalou et al., 1993), and up to 300 years in more stable, slow spreading ridges such as the Mid-Atlantic Ridge (Brazelton et al., 2010). These common temporal fluctuations in vent activity and changes in the geochemical profile of their habitat prevent long-term local population persistence (Tunnicliffe, 1991; Jollivet, 1996). Those species that escape local extinction due to habitat disappearance and which are capable of (re)colonizing newly active sites may also have the capacity for long-distance effective migration. Species associated with hydrothermal vents should therefore also have good colonization abilities with high rates of dispersal, growth and fecundity (Vrijenhoek, 1997; Tyler \& Young, 1999). Indeed, in 1991 the formation of new hydrothermal vents in the East Pacific Rise was studied and, astonishingly, microbe-derived material was found in active areas of the vent immediately following their formation. Within the first year, mobile vent and non-vent fauna such as amphipods, copepods, crabs and non-vent shrimps then proliferated (Shank et al., 1998a). These vastly differing sources of influence lead to contradictory expectations about strategy, which have yet to be tested. On one hand, low effective dispersal and high self recruitment may be favoured across limited distances due to the patchy nature of vent distribution and abiotic characteristics. On the other hand, larger scale dispersal potential may be selected for in the long term, allowing species persistence despite instability of vent activity. Finally, temporal instability (Desbruyères et al., 1998), although apparently less pronounced in the Mid-Atlantic Ridge (MAR) than in the East Pacific Rise (EPR) (Copley et al., 2007 on one site), may also result in shortterm changes in genetic composition. 
Along the Mid-Atlantic Ridge (MAR), vent communities are dominated by shrimps, mussels, anemones and crabs (Tunnicliffe, 1991; Van Dover, 1995). The first described and the most abundant species is the shrimp Rimicaris exoculata Williams \& Rona, 1986. This species is often present in high-density swarms $\left(>1500\right.$ individuals $\left./ \mathrm{m}^{2}\right)$ around high-temperature sulphide chimneys at deeper hydrothermal vent sites (Segonzac et al., 1993; Copley et al., 1997). The species has highly modified eyes that form a single dorsal organ, which has been suggested to detect blackbody radiation associated with high temperature vents (Van Dover et al., 1989; Van Dover, 1995). This shrimp does not seem to be a scavenger or a predator because its gut is filled with minerals, mainly iron oxides and sulphurs, and its nutrition is hypothesized to be derived from several epibiotic bacterial sources, mainly those located in the gill chambers and gut (see Durand et al., 2010 and references therein). Although hydrothermal vents at MAR have been known since 1985 (Rona et al., 1986), little is known about population genetic structure of its most abundant shrimp species. Genetic studies conducted to date have focused on clarifying the systematic status of the juvenile morphotype of $R$. exoculata (Creasey et al., 1996; Shank et al., 1998b). The allozyme analyses conducted in these studies showed very low genetic diversity within sites and essentially no genetic differentiation between populations, suggesting that there is high gene flow.

The main goal of this study was to infer the spatial and temporal distribution of genetic diversity of $R$. exoculata from different hydrothermal vents along the Mid-Atlantic Ridge, in order to assess the extent of effective population sizes, rates of dispersal and recent demographic histories at these sites. We used mitochondrial cytochrome $c$ oxidase subunit I (COI) as a molecular marker to estimate the level of genetic variability in natural populations, to test for genetic subdivision and to obtain insights into population history, dynamics and demography at the ridge level. In order to assess the effect of potential temporal instability of hydrothermal activity and population dynamics of associated species, two of the five populations studied were analysed at time intervals of one or ten years.

\section{Materials and Methods}

\subsection{Sampling and DNA extraction}

Samples were collected from five locations corresponding to different hydrothermal vent fields (Rainbow, Logatchev, TAG, Ashadzé and South MAR) along the Mid-Atlantic Ridge (Fig. 1, Table 1). For two locations (Rainbow and Logatchev), samples from different years were used to assess temporal variability; a time interval of 10 years (Rainbow 1997 and 2007) and 3 consecutive one year intervals (Logatchev 2005, 2006, 2007) were used. Samples were collected using a slurp-gun from the ROV (Remotely Operated Vehicle) or the Nautile. Prior to each dive, the bowls used for collecting the shrimps were aseptically washed with ethanol (96\%) before being filled with sterile seawater. Once on board, live specimens were either entirely frozen or immediately dissected into body components under sterile conditions and frozen or stored in $70 \%$ alcohol. DNA extraction was performed using the CTAB (cetyl trimethyl ammonium bromide) method (Doyle \& Doyle, 1990) on muscle tissue. Sampling size could not be pre-defined to a constant value across all sampling sites and times due to the overall difficulty in obtaining samples from deep hydrothermal vents; in some sites sampling size was thus limited to the shrimp samples available from Ifremer research cruises for each particular location and time, and (for the $4{ }^{\circ} \mathrm{S}$ location) some samples kindly provided by Max Plank Institute (N. Dubilier).

\subsection{Polymerase chain reaction and sequencing}

Mitochondrial COI was amplified using the universal primers LCO1490 and HCO2198 described by Folmer et al. (1994). All polymerase chain reaction (PCR) amplifications were carried out in $50 \mu \mathrm{L}$ volumes containing $50 \mathrm{ng}$ DNA, $1 \times$ reaction buffer (GoTaq, Promega), $0.2 \mathrm{mM}$ of each dNTP, 2.5 $\mathrm{mM} \mathrm{MgCl}_{2}, 0.4 \mathrm{U}$ Taq DNA polymerase (GoTaq, Promega, Madison, WI, USA) and $0.6 \mu \mathrm{M}$ of each 
primer. The PCR amplification was conducted in a Perkin-Elmer Gene Amp System 7200 (Waltham, MA, USA) with the following program: $2 \mathrm{~min}$. at $95^{\circ} \mathrm{C}$; 35 cycles composed of 1 min denaturation at $95^{\circ} \mathrm{C}, 1 \mathrm{~min}$ at $52^{\circ} \mathrm{C}$ and $1.5 \mathrm{~min}$ elongation at $72^{\circ} \mathrm{C}$, followed by a final elongation step of $7 \mathrm{~min}$ at $72^{\circ} \mathrm{C}$. PCR products were sent to be purified and sequenced commercially at Macrogen, Inc. (Seoul, Korea). Sequences were proofread and aligned using Geneious software (Drummond et al., 2009). The 18S rDNA ( 1.7 kb) was amplified for 4 individuals of all sampled locations and years (except for the Ashadzé population, where only the three individuals available were amplified) using 18S-82F/18S-1498R primers (López-García et al., 2003) and sequenced in an ABI $3130 \mathrm{XL}$ automatic sequencer (Applied Biosystems, Foster City, CA, USA), to provide hints into nuclear variation. The nuclear regions ITS 1 and 2 ( $931 \mathrm{bp})$ were also amplified for four individuals of three populations (Rainbow, Logatchev and South MAR) using the primer pair ITS 1 and 4 (Kumar \& Shukla, 2005). The obtained sequences were cloned (PGem-T easy vector, Promega) following the supplier's protocol; four clones per individual were sequenced using the $A B I 3130 \mathrm{XL}$ automatic sequencer (Applied Biosystems).

No diversity was detected across the 4 individuals from the 5 sites sequenced for $1200 \mathrm{bp}$ of $18 \mathrm{~S}$ rDNA. The amplified regions ITS1 and 2 proved to be too variable to be used: all the sequences obtained were different, including sequences from different clones of the same individual.

\subsection{Data analysis}

ARLEQUIN version 3 (Schneider et al., 2000) was used to estimate gene diversity and conduct statistical tests. For each population, the following statistics were computed: haplotype $(h)$ (Nei, 1987) and nucleotide diversities $\left(\pi_{2}\right)$ (Nei, 1987), and mean number of pairwise differences $\left(\pi_{1}\right)$ (Tajima, 1983). For populations with significantly different sample sizes, a re-sampling method was applied using $\mathrm{R}$ to generate files for 100 random re-samplings of the population haplotype frequencies to a minimum common size. The 100 generated files were then analysed with the batch file function of ARLEQUIN software to re-estimate gene diversity in these sub-samples. To assess population differentiation, pairwise $F_{\mathrm{ST}}$ values were calculated following the method of Hudson et al. (1992) and exact tests of differentiation were conducted following the method of Raymond \& Rousset (1995).

In order to analyse and illustrate the phylogenetic relationships among haplotypes, i) a medianjoining network was constructed using Network v. 4.1.0.9 (Bandelt et al., 1999) to infer the most parsimonious branch connections between the sampled haplotypes, and ii) a neighbour-joining phylogram was constructed using the mutation model HKY (Geneious software; Drummond et al., 2009) and the bresiliid sister species Alvinocaris sp. as an outgroup.

We tested whether the sampled populations fitted mutation drift equilibrium expectations, and assessed which population demographic model was most appropriate, i.e. the size-stationary model or the expansion model. We determined Fu's $F_{s}(F u, 1996)$ and Tajima's $D$ (Tajima, 1989), which are sensitive to departures from both selective neutrality and from population size equilibrium caused by expansions or bottlenecks (Tajima, 1996; Fu, 1997). Both statistics result in negative values after a population expansion (Ray et al., 2003) or a selective sweep, whereas positive values are expected under balancing selection of recent bottlenecks. ARLEQUIN was used to perform tests and estimate the associated $P$-values. Mismatch curves were drawn for each population and observed values were compared to the expected curves fitted for the constant population size model and for the population growth/decline model, using the DnaSP 4.0 program (Rozas et al., 2003). 


\subsection{Genetic diversity and population differentiation}

A total of 47 haplotypes were recovered from the 152 individuals analysed, $30(63.8 \%)$ of the haplotypes were "private", i.e. unique to a single locality (Table 2; Fig. 1; accession numbers: HM125910 to HM125956). The most common haplotype was present in all population samples and was the most abundant haplotype across all populations, identified in $49 \%$ of all the sampled individuals across the entire study region. This main haplotype was also central to all other haplotypes, most of these represented by a single individual and divergent by a single point mutation, leading to this haplotype being the core of a star-like cluster topography (Fig. 2). The remaining haplotypes (36.2\%), although not unique, were mainly $(27.7 \%)$ represented by only one individual in each population. Accordingly, the neighbour-joining phylogram revealed extremely unresolved clusters supported by poor bootstrap values (see Appendix S1 in Supporting Information).

At a temporal scale of a 10-year sampling interval (Rainbow 1997 and 2007), the unique haplotypes (present in one year and not on the other) represented $56 \%$ of the total haplotypes found, whereas on the temporal scale of a one year sampling interval (Logatchev 2005, 2006, 2007) the proportion of unique haplotypes was higher (88.5\%).

Haplotype diversity $(h)$ was high, ranging from 0 to 1 in populations with small sample sizes (Ashadzé: 3 individuals and 1 haplotype; South MAR: 4 individuals and 4 haplotypes) and 0.69 to 0.82 in populations with larger sample sizes ( $>11$ individuals). Considering these rather high values of haplotype diversity, nucleotide diversity $\left(\pi_{2}\right)$ was low, ranging from 0 to 0.0033 (Table 2). Highest diversities were recorded in the South MAR population, although the sample size was very low (4 individuals), followed by the Rainbow 2007 population. Populations sampled in more than one year presented different diversity indices across years. The Rainbow population sampled in 2007 showed more polymorphic sites, and higher haplotype and nucleotide diversity than when it was sampled in 1997, even though the number of samples was lower in 2007 (26 individual) than in 1997 (32 individual). A random re-sampling method was therefore not needed for Rainbow, as the sample with the fewest individuals already presented the higher diversity indices. Random resampling was, however, performed for Logatchev, where samples had more contrasting sizes (12 to 31 individuals) with no obvious diversity trend through time. In order to dissociate a putative biological effect from a sampling size effect, the random re-sampling (100 times) was therefore performed to a minimum common size of 12 individuals per sampling time, and no significant differences were found in any of the diversity indices over time (Table 3).

No significant population differentiation was detected between any of the sampling sites or years using pairwise $F_{\mathrm{ST}}$ estimates (Table 4 ).

\subsection{Historical demography}

Demographic analyses suggested the occurrence of population expansions, as highly significant negative values for Tajima's $D$ and Fu's $F_{S}$ were obtained for all populations (Table 2). Mismatch distribution curves were consistent with models of population expansion, displaying a unimodal distribution (Fig. 3). When comparing the expected and observed mismatch curves under constant population size versus the growth/decline model (Fig. 4), there is an excess of rare variants in the observed curves in relation to that expected under constant population size. Furthermore, the observed curves seem to better follow the expected curve for the growth/decline model. 


\section{Discussion}

The analysis of mtDNA haplotypes from a total of 152 individuals from five discrete vent localities along the Mid-Atlantic Ridge showed an overall high genetic variability within the studied populations. Both the number of haplotypes per population (1 to 16) and gene diversity (0.69 to 0.82 ) are within the range of values found for other vent organisms studied with the same marker, including tubeworms (e.g. Riftia pachyptila, Alvinella pompejana), limpets (e.g. Lepetodrillus elevatus) and bivalves (e.g. Bathymodiolus azoricus, Calyptogena magnifica) (e.g. Hurtado et al., 2004; Johnson et al., 2006; Plouviez et al., 2009). However, these results contradict those obtained for Rimicaris exoculata with allozymes, where genetic variability was amongst the lowest reported for vent organisms (Creasey et al., 1996). This may be due to the different properties of the distinct markers because allozymes may exhibit lower polymorphism than mtDNA, possibly associated with protein constraints. Mitochondrial DNA polymorphism is classically considered as less influenced by possible selective processes (Ballard \& Whitlock, 2004), although it was recently demonstrated that this may not be a systematic rule (Galtier et al., 2009). In any case, DNA sequences retain more polymorphisms than proteins, as polymorphic DNA sequences include synonymous mutations; higher variability can, therefore, be detected by DNA sequences than by allozymes. On the other hand, a differential imprint of demographic events on mitochondrial versus nuclear DNA may be evoked, although lower diversity is usually expected for mtDNA in relation to nuclear DNA, due to the difference in effective population size. Such discrepancies may also be affected by the more restricted sampling that was available for the allozyme study, which included only two sampling locations despite the higher overall number of samples analysed (448 individuals).

The rather unresolved phylogram, with low bootstrap values, shows a generally low divergence without a geographical imprint. Together with the non-significant $F_{\mathrm{ST}}$ values obtained in this study, these results indicate a lack of geographic partitioning of the numerous but slightly divergent haplotypes among the sampled populations. This lack of genetic structure may be due to several non-mutually exclusive factors: high levels of effective dispersal (gene flow) between all populations of the Mid-Atlantic ridge, i.e., panmixia at the ridge level; large effective population sizes $\left(N_{\mathrm{e}}\right)$; and/or recent common population history. The life cycle of Rimicaris is poorly understood. Some authors have suggested that $R$. exoculata might feed in the upper water column during larval dispersal (Dixon \& Dixon, 1996), and others that the juvenile stages of these shrimp differ physiologically from the adults (Pond et al., 1997; Allen et al., 1998) in traits such as wax-ester reserves and possibly photosynthetically derived lipids. These findings led the authors to hypothesize that the species had a long planktotrophic phase with long-distance migration achieved via the surface, so that some of the barriers usually considered, (depth, seafloor topology and transform faults) would not constrain this species. Yet, such a hypothesis implies either a huge risk factor in the case of passive dispersal, or an extremely sophisticated mechanism of active and deterministic migration (that has not been identified so far) allowing a return to hydrothermal habitat at the end of larval development. In any case, whether dispersal occurs via the surface or not, the little information available to date on $R$. exoculata suggests a significant dispersal potential either at larval or at adult stage (although no observations of adults away from hydrothermal sites have been reported so far).

The low degree of genetic differentiation among populations may also be attributed to a relatively recent common history together with large effective population sizes, which limit genetic drift (Crow, 1986). The scenario of (1) high levels of gene flow and that of (2) low gene flow since a recent divergence and large $N_{\mathrm{e}}$ may both leave similar signatures of low genetic structure of populations. The hypothesis of large effective population sizes limiting drift is concordant with the population biology of this species, as $R$. exoculata is reported to have remarkably high population densities of over 1500 individuals $/ \mathrm{m}^{2}$ (Copley et al., 1997). Such large population sizes may, in the absence of temporal fluctuation or significant variance in reproductive success, result in large effective population sizes, limiting the differentiating effects of drift. Yet, the haplotype phylogram and network, together with the analyses of population history, indicate a recently very low effective population size as they show: (1) a star-like haplotype network where many new haplotypes are 
derived from one dominant haplotype via single mutation steps, indicating that they are the product of recent mutation events; (2) negative and highly significant values of Tajima's $D$ and Fu's $F_{S}$ tests, as expected under population bottleneck/expansion scenarios; and (3) the expected and observed mismatch curves that follow a growth/decline model. This profile supports a scenario of relatively young populations sharing a recent common history of bottleneck or founder events, and expansion. Recent study of epibionts of the $R$. exoculata gill chamber (Petersen et al., 2009) showed spatial clustering of bacterial sequences across the different sites (Rainbow, Logatchev and South MAR). Such geographical segregation of the symbionts compared to host homogeneity may be due either to the influence of environment on symbionts, or to the very recent common history of $R$. exoculata populations with recent divergence only detectable on short generation symbionts but still undetectable on the genetics of their hosts.

The analysis of temporal variability revealed a lack of genetic differentiation among samples separated by time steps of one (Logatchev) and ten years (Rainbow), although within population diversity increased within a decade in Rainbow. In contrast to Logatchev, where no significant differences were observed across three consecutive years, Rainbow exhibited a significantly higher genetic diversity in 2007 compared with ten years earlier, despite the lower sample size and equal number of haplotypes (but more evenly distributed) in 2007. Genetic diversity, quantified both in terms of allelic richness and heterozygosity, increased significantly over the ten year interval in Rainbow, in agreement with a possible ongoing effect of population expansion (Table 2). Such trends were not detected in the diversity indices for the one year interval samples, possibly indicating that temporal variations in diversity are not sufficiently large to be detected over the shorter time scale of one year intervals. The pattern of variability across temporal samples therefore suggests a contemporary expansion, over one decade, at least in Rainbow. However, population growth tests are known not to perform well when population expansion is very recent (RamosOnsins \& Rozas, 2002), and any expansion episodes detected using the growth decline model are, therefore, likely to be older than a decade. Altogether, with the star-like cluster of haplotypes revealing the accumulation of mutations over a recent evolutionary scale, these results imply either successive episodes of expansion or one long-term expansion episode affecting the pattern of haplotype diversity at both ecological and evolutionary time scales.

Considering the demographic history of these apparently rather young genetic lineages, which have probably undergone rather recent recolonization and/or expansion events, the lack of genetic differentiation among sites does not allow us to make inferences about the ongoing occurrence of extensive or restricted gene flow among the hydrothermal sites distributed along the Mid-Atlantic Ridge. Yet, in the absence of any selective hypothesis explaining the star-like pattern of COI polymorphism, the hypothesis of such a recent and global (re)colonization also implies a high dispersal potential per se in the rather recent past. Recent bottlenecks and/or expansion have also been observed across populations of several hydrothermal invertebrates along other oceanic ridges (Young et al., 2008; Faure et al., 2009; Plouviez et al., 2009) and such profiles of young lineages may be a rule rather than an exception for hydrothermal vent-associated species, due to the dynamic nature of vents subject to recurrent extinction events. In other ridges, such as the East Pacific Rise, most species studied to date also display a clear North/South genetic differentiation and in some cases even highly significant $F_{\mathrm{ST}}$ values within the north and south populations (Hurtado et al., 2004; Matabos et al., 2008; Plouviez et al., 2009). This genetic differentiation reported among populations of different vent species may be due to a lower dispersal potential and/or effective population size of these organisms, or to a higher occurrence or strength of physical and abiotic barriers to gene flow, such as transform faults, in the East Pacific Rise than in the MidAtlantic Ridge (but see O'Mullan et al., 2001). Other species, however, do not exhibit such cleavage (Won et al., 2003; Hurtado et al., 2004; Plouviez et al., 2009), which may indicate a species-specific characteristic (such as dispersal potential or population size), or might simply reflect different sampling schemes. Large gaps in the sampling were indeed observed for most species where a north/south cleavage was shown and such a sampling scheme was demonstrated by Audzijonyte \& Vrijenhoek (2010) to have the potential to result in artificially inflated $F_{\mathrm{ST}}$ values. Yet, in the study of the sister mussel species Bathymodiolus azoricus and B. puteoserpentis and their hybrids (O'Mullan 
et al., 2001), the clear distinction in species distribution between north (Rainbow, Lucky strike and Menez Gwen vents) and south (Snake Pit and Logatchev vents) along the MAR, suggests the existence of an ancient vicariance event that apparently does not affect Rimicaris exoculata, possibly due to a more recent history, higher effective population sizes, or higher dispersal potential in this shrimp species.

As few species have been studied so far in the MAR compared with the more extensively studied East Pacific Rise (EPR), a generalized comparison is not yet possible, but a species-specific hypothesis may be put forward to explain the lack of structure observed for $R$. exoculata. High dispersal potential, including long-distance migration as a bet-hedging strategy enabling escape from extinction, is thought to be a factor of risk in a fragmented environment due to the possible loss of progeny in non suitable habitats. In $R$. exoculata, this risk may be compensated by a high fecundity, as suggested for other species (Llodra et al., 2000), and/or by an environmentally driven delay in larval development, suggested by O'Connor et al. (2007) to be a possible adaptation associated with large scale dispersal. Moreover, it has been suggested that $R$. exoculata may detect black-body radiation associated with high-temperature vents (Van Dover et al., 1989, Herring et al., 1999); this may be a specific adaptation of this species to locate its exceptional habitat during large scale dispersal, allowing the benefit of the large scale dispersal to be kept while minimizing the associated risk of loss at the time of settlement. However, empirical data have shown that the detection of temperature in seawater may only be possible within a small area around the chimneys where the seawater is actually warmer (Segonzac et al., 1993). The putative mechanism that may allow $R$. exoculata larvae to settle in their habitat after this hypothetical long-distance dispersal is therefore not elucidated, it may be temperature-associated or based on chemical signals linked to the presence of adults, as has been demonstrated for other marine invertebrates such as the oyster Ostrea puelchana, where preferential settlement of spat occurs close to the adults due to a chemical stimulus (Pascual \& Zampatti, 1995).

This study makes a novel contribution to our understanding of the biogeography of the Mid-Atlantic Ridge by providing new insight into the population biology and biogeographic structure of a key species of shrimp from the unique, extreme and remote marine habitats of hydrothermal vents. Our results indicate that, across this very remote biogeographic region, all vent populations of this shrimp have a recent common history derived from a bottleneck or founder event, followed by a demographic expansion toward apparently large effective population sizes. Associated with high dispersal potential, such history possibly results in the absence of significant drift effects. Interestingly, these results may indicate a possible common source or centre of origin of a (re)colonization event at the origin of the lineages sampled from the MAR in our study. The identification of such a potential source population is, unfortunately, rendered particularly difficult in these ecosystems because the sampling of hydrothermal vents is necessarily as fragmented in space and time as the ecosystems themselves are. Finally, more species should be studied on the MAR to compare results with the more extensively studied EPR (East Pacific Rise) in order to test for the possible influence of the shape of ridges and transform faults on the pattern of evolution and genetic differentiation of species associated with hydrothermal vents.

\section{Acknowledgements}

The authors wish to thank Alex Canton, Rui Candeias, Olivier Mouchel, Valérie Cueff-Gauchard and Stéphane L'Harridon, for technical help in the lab; Filipe Alberto for help with R; Didier Jollivet and Stéphane Hourdez for interesting discussions; Jillian Petersen and Nicole Dubilier for kindly providing samples from South MAR; the captain and crews of the vessels R/V Atalante, Pourquoi Pas? and Meteor, and the crew of the submersible Nautile and ROV Victor6000; and the cruise chiefs D. Desbruyers, A. Godfroy, Y. Fouquet, F. Gaill and J. Dyment for the cruises MARVEL 1997, EXOMAR 2005, SERPENTINE 2007, and MoMARDREAM-Naut 2007, respectively. We also thank Robert Vrijenhoek and an anonymous referee for the helpful comments and suggestions on this 
manuscript and Helen McCombie for the professional editing of this manuscript. S.T. was supported by a postdoctoral fellowship from FCT, Portuguese Science Foundation and ESF (European Social Fund), S.T, M-A C-B. and S.A-H were supported by Ifremer funds (DeepOases, ANR project).

\section{References}

Allen, C.E., Copley, J.T.P., Tyler, P.A. \& Varney, M.S. (1998) Lipid profiles of hydrothermal vent shrimps. Cahiers de Biologie Marine, 39, 229-231.

Audzijonyte, A. \& Vrijenhoek, R.C. (2010) When gaps really are gaps: statistical phylogeography of hydrothermal vent invertebrates. Evolution, doi: 10.1111/j.1558-5646.2010.00987.x.

Bachraty, C., Legendre, P. \& Desbruyères, D. (2009) Biogeographic relationships among deep-sea hydrothermal vent faunas at global scale. Deep-Sea Research I, 56, 1371 -1378.

Ballard, J.W. \& Whitlock, M.C. (2004) The incomplete natural history of mitochondria. Molecular Ecology, 13, 729-744.

Bandelt, H.J., Forster, P. \& Röhl, A. (1999) Median-joining networks for inferring intraspecific phylogenies. Molecular Biology and Evolution, 16, 37-48.

Billiard, S. \& Lenormand,T. (2005) Evolution of migration under kin selection and local adaptation. Evolution, 59,13-23.

Brazelton, W.J., Ludwig, K.A., Sogin, M.L., Andreishcheva, E.N., Kelley, D.S., Shen, C.-C., Edwards, R.L. \& Baross, J.A. (2010) Archaea and bacteria with surprising microdiversity show shifts in dominance over 1,000-year time scales in hydrothermal chimneys. Proceedings of the National Academy of Sciences USA, 107, 1612-1617.

Copley, J.T.P., Tyler, P.A., Murton, B.J. \& van Dover, C.L. (1997) Spatial and interannual variation in the faunal distribution at Broken Spur vent field (29N, Mid-Atlantic Ridge). Marine Biology, 129, 723-733.

Copley, J.T.P., Jorgensen, P.B.K. \& Sohn, R.A. (2007) Assessment of decadal-scale ecological change at a deep Mid-Atlantic hydrothermal vent and reproductive time-series in the shrimp Rimicaris exoculata. Journal of the Marine Biological Association of the United Kingdom, 87, 859867.

Creasey, S., Rogers, A.D. \& Tyler, P.A. (1996) Genetic comparison of two populations of the deepsea vent shrimp Rimicaris exoculata (Decapoda: Bresiliidae) from the Mid-Atlantic Ridge. Marine Biology, 125, 473-482.

Crow, J. (1986) Basic concepts in population, quantitative, and evolutionary genetics. Freeman, San Francisco, CA.

Desbruyères, D., Chevaldonné, P., Alayse, A.-M., Jollivet, D., Lallier, F.H., Jouin-Toulmond, C., Zal, F., Sarradin, P.-M., Cosson, R., Caprais, J.-C, Arndt, C., O'Brien, J., Guezennec, J., Hourdez, S., Riso, R., Gaill, F., Laubier, L. \& Toulmond, A. (1998) Biology and ecology of the "Pompeii worm" (Alvinella pompejana Desbruyères and Laubier), a normal dweller of an extreme deep-sea environment: A synthesis of current knowledge and recent developments. Deep-Sea Research II, 45, 383-422. 
Desbruyères, D., Almeida, A., Biscoito, M., Comtet, T., Khripounoff, A., Le Bris, N., Sarradin, P.M. \& Segonzac, M. (2000) A review of the distribution of hydrothermal vent communities along the northern Mid-Atlantic Ridge: dispersal vs. environmental controls. Hydrobiologia, 440, 201-216.

Dixon, D.R. \& Dixon, L.R.J. (1996) Results of DNA analyses conducted on vent shrimp postlarvae collected above the Broken Spur vent field during the CD95 cruise, August 1995. BRIDGE Newsletter, 11,9-15.

Doyle, J.J. \& Doyle, J.L. (1990) Isolation of plant DNA from fresh tissue. Focus, 12, 13-15.

Drummond, A.J., Ashton, B., Cheung, M., Heled, J., Kearse, M., Moir, R., Stones-Havas, S., Thierer, T. \& Wilson, A. (2009) Geneious v4.7. http://www.geneious.com/.

Durand, L., Zbinden, M., Cueff-Gauchard, V., Duperron, S., Roussel, E.G., Shillito, B. \& CambonBonavita, M.-A. (2010) Microbial diversity associated with the hydrothermal shrimp Rimicaris exoculata gut and occurrence of a resident microbial community. FEMS Microbiology and Ecology, 71, 291-303.

Fabri, M.C., Galéron, J., Larour, M. \& Maudire, G. (2006) Combining the Biocean database for deep-sea benthic data with the online Ocean Biogeographic Information System. Marine Ecology Progress Series, 316, 215-224.

Faure, B., Jollivet, D., Tanguy, A., Bonhomme, F. \& Bierne, N. (2009) Speciation in the deep sea: multi-locus analysis of divergence and gene flow between two hybridizing species of hydrothermal vent mussels. PLoSONE 4(8), e6485. doi:10.1371/journal.pone.0006485.

Folmer, O., Hoeh, W.R., Black, M.B. \& Vrijenhoek, R.C. (1994) Conserved primers for PCR amplification of mitochondrial DNA from different invertebrate phyla. Molecular Marine Biology and Biotechnology, 3, 294-299.

Fu, Y.X. (1996) New statistical tests of neutrality for DNA samples from a population. Genetics, 143, 557-570.

Fu, Y.X. (1997) Statistical tests of neutrality of mutations against population growth, hitchhiking and background selection. Genetics, 147, 915-925.

Galtier, N., Nabholz, B., Glémin, S. \& Hurst, G.D.D. (2009) Mitochondrial DNA as a marker of molecular diversity: a reappraisal. Molecular Ecology, 18, 4541-4550.

Garant, D., Forde, S.E. \& Hendry, A.P. (2007) The multifarious effects of dispersal and gene flow on contemporary adaptation. Functional Ecology, 21,434-443.

Hamilton, W.D. \& May, R.M. (1977) Dispersal in stable habitats. Nature, 269,578-581.

Herring, P.J., Gaten, E., \& Sheldon, P.M.J. (1999) Are vent shrimps blinded by science? Nature, $398,116$.

Hessler, R.R., Smithey, W.M., Boudrias, M.A., Keller, C.H., Lutz, R.A. \& Childress, J.J. (1988) Temporal change in megafauna at the rose garden hydrothermal vent (Galapagos Rift; eastern tropical Pacific). Deep-Sea Research, 35, 1681-1709.

Hudson, R.R., Slatkin, M. \& Maddison, W.P. (1992) Estimation of levels of gene flow from DNAsequence data. Genetics, 132,583-589. 
Hurtado, L., Lutz, R. \& Vrijenhoek, R. (2004) Distinct patterns of genetic differentiation among annelids of eastern Pacific hydrothermal vents. Molecular Ecology, 13, 2603-2615.

Ims, R.A. \& Andreassen, H.P. (2000) Spatial synchronization of vole population dynamics by predatory birds. Nature, 408, 194-196.

Johnson, S.B., Young, C.R., Jones, W.J., Waren, A. \& Vrijenhoek, R.C. (2006) Migration, isolation, and speciation of hydrothermal vent limpets (Gastropoda; Lepetodrilidae) across the Blanco transform fault. The Biological Bulletin, 210, 140-157.

Jollivet, D. (1996) Specific and genetic diversity at deep-sea hydrothermal vents: an overview. Biodiversity and Conservation, 5, 1619-1653.

Jollivet, D., Chevaldonné, P. \& Planque, B. (1999) Hydrothermal-vent alvinellid polychaete dispersal in the eastern Pacific. 2. A metapopulation model based on habitat shifts. Evolution, 53, 1128-1142.

Kumar, M. \& Shukla, P.K. (2005) Use of PCR targeting of internal transcribed spacer regions and single-stranded conformation polymorphism analysis of sequence variation in different regions of rRNA genes in fungi for rapid diagnosis of mycotic keratitis. Journal of Clinical Microbiology, 43, 662-668.

Lalou, C., Reyss, J-L., Brichet, E., Arnold, M., Thompson, G., Fouquet, Y. \& Rona, P.A. (1993) New age data for Mid-Atlantic Ridge hydrothermal sites: TAG and Snakepit chronology revisited. Journal of Geophysical Research, 98, 9705-9713.

Llodra, E.R., Tyler, P.A. \& Copley, J.T.P. (2000) Reproductive biology of three caridean shrimp, Rimicaris exoculata, Chorocaris chacei and Mirocaris fortunata (Caridea: Decapoda), from hydrothermal vents. Journal of the Marine Biological Association of the United Kingdom, 80, 473484.

López-García, P., Philippe, H., Gail, F. \& Moreira, D. (2003) Autochthonous eukaryotic diversity in hydrothermal sediment and experimental microcolonizers at the Mid-Atlantic Ridge. Proceedings of the National Academy of Sciences USA, 100, 697-702.

Matabos, M., Thiébaut, E., Le Guen, D., Sadosky, F., Jollivet, D. \& Bonhomme, F. (2008) Geographic clines and stepping-stone patterns detected along the East Pacific Rise in the vetigastropod Lepetodrilus elevatus reflect species crypticism. Marine Biology 153, 545-563.

Nei, M. (1987) Molecular evolutionary genetics. Columbia University Press,New York.

Olivieri, I., Michalakis, Y. \& Gouyon, P.H. (1995) Metapopulation genetics and the evolution of dispersal. The American Naturalist, 146, 202-228.

O'Connor, M.I., Bruno, J.F., Gaines, S.D., Halpern, B.S., Lester, S.E., Kinlan, B.P. \& Weiss, J.M. (2007) Temperature control of larval dispersal and the implications for marine ecology, evolution, and conservation. Proceedings of the National Academy of Sciences USA, 104, 1266-1271.

O'Mullan, G.D., Maas, P.A.Y., Lutz, R.A. \& Vrijoenhoek, R.C. (2001) A hybrid zone between hydrothermal vent mussels (Bivalvia: Mytilidae) from the Mid-Atlantic Ridge. Molecular Ecology, 10, 2819-2831.

Pascual, M.S. \& Zampatti, E.A. (1995) Evidence of a chemically mediated adult-larval interaction triggering settlement in Ostrea puelchana: applications in hatchery production. Aquaculture, 133, 33-44. 
Petersen, J.M., Ramette, A., Lott, C., Cambon-Bonavita, M.-A., Zbinden, M. \& Dubilier, N. (2009) Dual symbiosis of the vent shrimp Rimicaris exoculata with filamentous gamma- and epsilonproteobacteria at four Mid-Atlantic Ridge hydrothermal vent fields. Environmental Microbiology, doi:10.1111/j.1462-2920.2009.02129.x

Pond, D., Dixon, D. \& Sargent, J. (1997) Wax-ester reserves facilitate dispersal of hydrothermal vent shrimps. Marine Ecology Progress Series, 146, 289-290.

Plouviez, S., Shank, T.M., Faure, B., Daguin-Thiébaut, C., Viard, F., Lallier, F.H. \& Jollivet, D. (2009) Comparative phylogeography among hydrothermal vent species along the East Pacific Rise reveals vicariant processes and population expansion in the South. Molecular Ecology, 18, 39033917.

Ramos-Onsins, S.E. \& Rozas, J. (2002) Statistical properties of new neutrality tests against population growth. Molecular Biology and Evolution, 19, 2092-2100.

Ray, N., Currat, M. \& Excoffier, L. (2003) Intra-deme molecular diversity in spatially expanding populations. Molecular Biology and Evolution, 20, 76-86.

Raymond, M. \& Rousset, F. (1995) Genepop (version 3.2): population genetics software for exact tests and ecumenicism. Journal of Heredity, 86, 248-249.

Rona, P.A., Klinkhammer, G., Nelsen, T.A., Trefry, J.H. \& Elderfield, H. (1986) Black smokers, massive sulphides and vent biota at the Mid-Atlantic Ridge. Nature, 321, 33-37.

Ronce, O. \& Olivieri, I. (2004) Life history evolution in metapopulations. Ecology, genetics, and evolution of metapopulations (ed. by I. Hanski and O.E. Gaggiotti), pp. 227- 258. Amsterdam Academic, Amsterdam.

Rozas, J., Sánchez-DelBarrio, J.C., Messeguer, X. \& Rozas, R. (2003) DnaSP, DNA polymorphism analyses by the coalescent and other methods. Bioinformatics, 19, 2496-2497.

Schneider, S., Roessli, D. \& Excoffier, L. (2000) Arlequin (V2.0): Software for population genetics data analysis. Genetics and biometry laboratory, Department of Anthropology, University of Geneva, Geneva.

Segonzac, M., DeSaintLaurent, M. \& Casanova, B. (1993) Enigma of the trophic adaptation of the shrimp Alvinocarididae in hydrothermal areas along the Mid-Atlantic Ridge. Cahiers de Biologie Marine, 34, 535-571.

Shank, T.M., Lutz, R.A. \&Vrijenhoek, R.C. (1998b) Molecular systematic of shrimp (Decapoda: Bresiliidae) from deep-sea hydrothermal vents, I: Enigmatic "small orange" shrimp from the MidAtlantic Ridge are juvenile Rimicaris exoculata. Molecular Marine Biology and Biotechnology, 7, 8896.

Shank, T.M., Fornari, D.J., Von Damm, K.L., Lilley, M.D., Haymon, R.M. \& Lutz, R.A. (1998a) Temporal and spatial patterns of biological community development at nascent deep-sea hydrothermal vents (950'N, East Pacific Rise). Deep-Sea Research II, 45, 465-515.

Tajima, F. (1983) Evolutionary relationships of DNA sequences in finite populations. Genetics, 105, 437-460 
Tajima, F. (1989) Statistical-method for testing the neutral mutation hypothesis by DNA polymorphism. Genetics, 123, 585-595.

Tajima, F. (1996) The amount of DNA polymorphism maintained in a finite population when the neutral mutation rate varies among sites. Genetics, 143, 1457-1465.

Tunnicliffe, V. (1991) The biology of hydrothermal vents: ecology and evolution. Oceanography and Marine Biology: Annual Review, 29, 319-407.

Tunnicliffe, V. \& Fowler, M.R. (1996) Influence of sea-floor spreading on the global hydrothermal vent fauna. Nature, 379, 531-533.

Tyler, P.A. \& Young, C.M. (1999) Reproduction and dispersal at vents and cold seeps. Journal of the Marine Biological Association of the United Kingdom, 79, 193-208.

Van Dover, C.L. (1995) Ecology of Mid-Atlantic Ridge hydrothermal vents. Hydrothermal vents and processes (ed by L.M. Parson, C.L. Walker and D.R. Dixon), pp. 257-294. Geological Society, London.

Van Dover, C.L. (2000) The Ecology of Deep-Sea Hydrothermal Vents. Princeton University Press, Princeton.

Van Dover, C.L., Szuts, E.Z., Chamberlain, S.C. \& Cann, J.R. (1989) A novel eye in 'eyeless' shrimp from hydrothermal vents of the Mid-Atlantic Ridge. Nature, 337, 458-460.

Van Dover, C.L., German, C.R., Speer, K.G., Parson, L.M. \& Vrijenhoek, R.C. (2002) Evolution and biogeography of deep-sea vent and seep invertebrates. Science, 295, 1253-1257.

Vrijenhoek, R.C. (1997) Gene flow and genetic diversity in naturally fragmented metapopulations of deep-sea hydrothermal vent animals. Journal of Heredity, 88, 285-293.

Williams, A.B. \& Rona, P.A. (1986) Two new caridean shrimps (Bresiliidae) from a hydrothermal vent field on the Mid-Atlantic Ridge. Journal of Crustacean Biology, 6, 446-462.

Won, Y., Young, C.R., Lutz, R.A. \& Vrijenhoek, R.C. (2003) Dispersal barriers and isolation among deep-sea mussel populations (Mytilidae: Bathymodiolus) from eastern Pacific hydrothermal vents. Molecular Ecology, 12, 169-184.

Young, C.R., Fujio, S. \& Vrijenhoek, R.C. (2008) Directional dispersal between mid-ocean ridges: deep-ocean circulation and gene flow in Ridgeia piscesae. Molecular Ecology, 17, 1718-1731.

\section{Supporting information}

Additional Supporting Information may be found in the online version of this article:

Appendix S1 Neighbour-joining phylogram constructed with $152 \mathrm{COI}$ mitochondrial sequences of Rimicaris exoculata

As a service to our authors and readers, this journal provides supporting information supplied by the authors. Such materials are peer-reviewed and may be re-organized for online delivery, but are not copy-edited or typeset. Technical support issues arising from supporting information (other than missing files) should be addressed to the authors. 


\section{Biosketches}

The researchers involved in this study have a long-standing interest in Biogeography, Ecology and Evolution of marine organisms and especially deep-sea hydrothermal vent communities (D.D.) and their symbiotic relationships (M.A-C.B). Author contributions: S.A-H. and D.D. conceived the ideas; M-A.C-B. collected most of the samples, S.T. collected the data; S.T., S.A.-H. and E.S. analysed the data; and all authors contributed to the writing.

Editor: Craig McClain

\section{Tables}

Table 1. Geographic coordinates, depth and cruise details for the populations of organisms sampled along the Mid-Atlantic Ridge.

\begin{tabular}{|c|c|c|c|c|}
\hline Population & Year & GPS coordinates & Depth & Cruise \\
\hline Rainbow & 2007 & $036^{\circ} 08^{\prime} 44^{\prime \prime} \mathrm{N} ; 034^{\circ} 00^{\prime} 02^{\prime \prime} \mathrm{W}$ & $2200 \mathrm{~m}$ & $\begin{array}{l}\text { MoMAR; ROV Victor6000; } \\
\text { RV Pourquoi pas? }\end{array}$ \\
\hline TAG & 2005 & 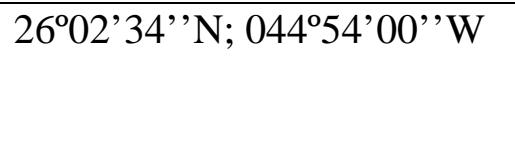 & $3650 \mathrm{~m}$ & $\begin{array}{l}\text { EXOMAR; ROV } \\
\text { Victor6000; RV L'Atalante }\end{array}$ \\
\hline $\begin{array}{l}\text { Logatchev } \\
\text { (Irina2) }\end{array}$ & 2007 & 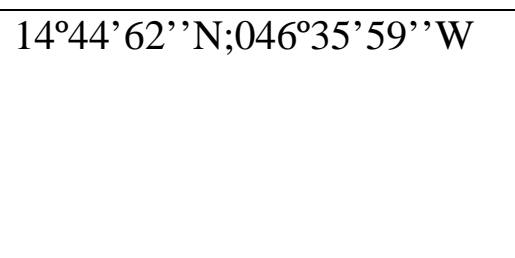 & $2860 \mathrm{~m}$ & $\begin{array}{l}\text { SERPENTINE; } \quad \text { ROV } \\
\text { Victor6000; RV Pourquoi } \\
\text { pas? }\end{array}$ \\
\hline Ashadzé (SE1) & 2007 & 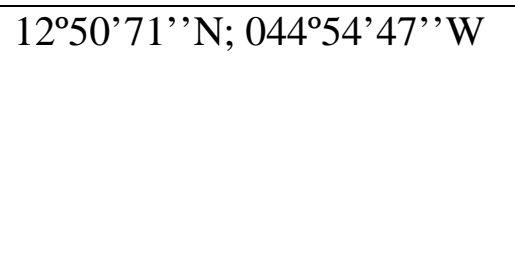 & $3200 \mathrm{~m}$ & $\begin{array}{l}\text { SERPENTINE; } r \text { ROV } \\
\text { Victor6000; RV Pourquoi } \\
\text { pas? }\end{array}$ \\
\hline SouthMAR & 2006 & $4^{\circ} 47^{\prime} \mathrm{S} ; 12^{\circ} 22^{\prime} \mathrm{W}$ & $3048 \mathrm{~m}$ & M64/1; ROV Meteor/Quest \\
\hline
\end{tabular}


Table 2. Genetic diversity indices calculated for each sampled population and year, of the deep-sea shrimp Rimicaris exoculata sampled along the Mid-Atlantic Ridge. (n) sample size; (Nh) number of haplotypes; (Nph) number of private haplotypes, i.e. the number of haplotypes that only appeared in one population; $(k)$ number of polymorphic sites; $(h)$ haplotype diversity; $\left(\pi_{1}\right)$ mean number of pairwise differences; $\left(\pi_{2}\right)$ nucleotide diversity. Neutrality and population expansion tests: $D=$ Tajima's D-test; $F_{S}=$ Fu's $F_{S}$ test. All values obtained for the neutrality tests were significant at the 5 $\%$ level.

\begin{tabular}{|l|l|l|l|l|l|l|l|l|l|l|}
\hline Population & Year & $\boldsymbol{n}$ & $\boldsymbol{k}$ & $\boldsymbol{N h}$ & $\boldsymbol{h}$ & $\boldsymbol{\pi}_{\mathbf{1}}$ & $\boldsymbol{\pi}_{2}$ & $\boldsymbol{D}$ & $\boldsymbol{F}_{\mathbf{S}}$ & $\boldsymbol{N} \mathbf{p h}$ \\
\hline Rainbow & 2007 & 26 & 18 & 14 & $0.82 \pm 0.07$ & 1.67 & 0.0033 & $-2.292(0.002)$ & $-11.01(0)$ & 3 \\
\hline & 1997 & 32 & 14 & 14 & $0.69 \pm 0.09$ & 1.05 & 0.0021 & $-2.298(0.001)$ & $-13.87(0)$ & 7 \\
\hline Logatchev & 2007 & 31 & 20 & 16 & $0.77 \pm 0.08$ & 1.41 & 0.0028 & $-2.487(0)$ & $-15.38(0)$ & 8 \\
\hline & 2006 & 12 & 9 & 7 & $0.77 \pm 0.13$ & 1.50 & 0.0030 & $-2.016(0.004)$ & $-3.52(0.003)$ & 3 \\
\hline TAG & 2005 & 13 & 8 & 8 & $0.81 \pm 0.11$ & 1.36 & 0.0027 & $-1.831(0.012)$ & $-5.25(0)$ & 3 \\
\hline Ashadzé & 2005 & 31 & 16 & 16 & $0.77 \pm 0.08$ & 1.09 & 0.0022 & $-2.454(0)$ & $-18.32(0)$ & 6 \\
\hline SouthMAR & 2006 & 4 & 3 & 4 & $1.00 \pm 0.18$ & 1.50 & 0.0030 & $-0.754(0.23)$ & $-2.37(0.008)$ & 0 \\
\hline
\end{tabular}

Table 3. Genetic diversity indices for the temporal samples of the population of Rimicaris exoculata from Logatchev. Diversity indices for the sampling years of 2005 and 2007 are given as averages $( \pm S D)$ due to the random re-sampling (100 times) to a minimum common size of 12 individuals per population. $(\mathrm{Nh})$ number of haplotypes; $(k)$ number of polymorphic sites; $(h)$ haplotype diversity; $\left(\pi_{2}\right)$ nucleotide diversity.

\begin{tabular}{|l|l|l|l|l|}
\hline \multicolumn{1}{|c|}{ Year } & \multicolumn{1}{c|}{ Nh } & \multicolumn{1}{c|}{ k } & \multicolumn{1}{c|}{$\boldsymbol{1}$} & \multicolumn{1}{c|}{$\boldsymbol{\pi}_{2}$} \\
\hline 2005 & $5.26 \pm 1.1$ & $5.1 \pm 1.46$ & $0.74 \pm 0.12$ & 0.0024 \\
\hline 2006 & 7 & 9 & $0.77 \pm 0.13$ & 0.0030 \\
\hline 2007 & $5.9 \pm 1.51$ & $6.78 \pm 2.25$ & $0.73 \pm 0.15$ & 0.0026 \\
\hline
\end{tabular}


Table 4. Pairwise $F_{\mathrm{ST}}$ values based on haplotype frequencies obtained for the species Rimicaris exoculata sampled along the Mid-Atlantic Ridge. None of the $F_{\mathrm{ST}}$ values were significant at the $5 \%$ level.

\begin{tabular}{|c|c|c|c|c|c|c|c|c|}
\hline Pops & $\begin{array}{c}\text { Rainbow } \\
07\end{array}$ & $\begin{array}{c}\text { Rainbow } \\
97\end{array}$ & $\begin{array}{c}\text { Logatchev } \\
07\end{array}$ & $\begin{array}{c}\text { Logatchev } \\
06\end{array}$ & $\begin{array}{c}\text { Logatchev } \\
05\end{array}$ & TAG & Ashadzé & $\begin{array}{l}\text { South } \\
\text { MAR }\end{array}$ \\
\hline Rainbow07 & & & & & & & & \\
\hline Rainbow97 & 0.00245 & & & & & & & \\
\hline Logatchev07 & -0.0115 & -0.01243 & & & & & & \\
\hline Logatchev06 & -0.0184 & -0.0221 & -0.0298 & & & & & \\
\hline Logatchev05 & -0.0335 & -0.0144 & -0.0227 & -0.0360 & & & & \\
\hline TAG & -0.0147 & -0.0138 & -0.0122 & -0.0262 & -0.0260 & & & \\
\hline Ashadzé & 0.0480 & -0.0230 & 0.0140 & 0.0145 & 0.0331 & $\begin{array}{l}0.014 \\
0\end{array}$ & & \\
\hline South MAR & -0.0589 & 0.0452 & 0.0031 & -0.0147 & -0.0495 & $\begin{array}{l}0.003 \\
1\end{array}$ & 0.250 & \\
\hline
\end{tabular}




\section{Figures}

Figure 1. Location of the Rimicaris exoculata populations sampled along the Mid-Atlantic Ridge, and the respective mtDNA haplotype distribution (pie charts) per population. The size of the pie charts is proportional to the number of individuals sampled from each population, and each colour in the pie charts represents a different haplotype; the singletons (haplotypes that appear only once in one population) are coded as white, the same haplotype found in different populations is represented, by the same colour in the corresponding pie charts. a) Key of the locations analysed along the MAR; b) colour key for the haplotypes found.

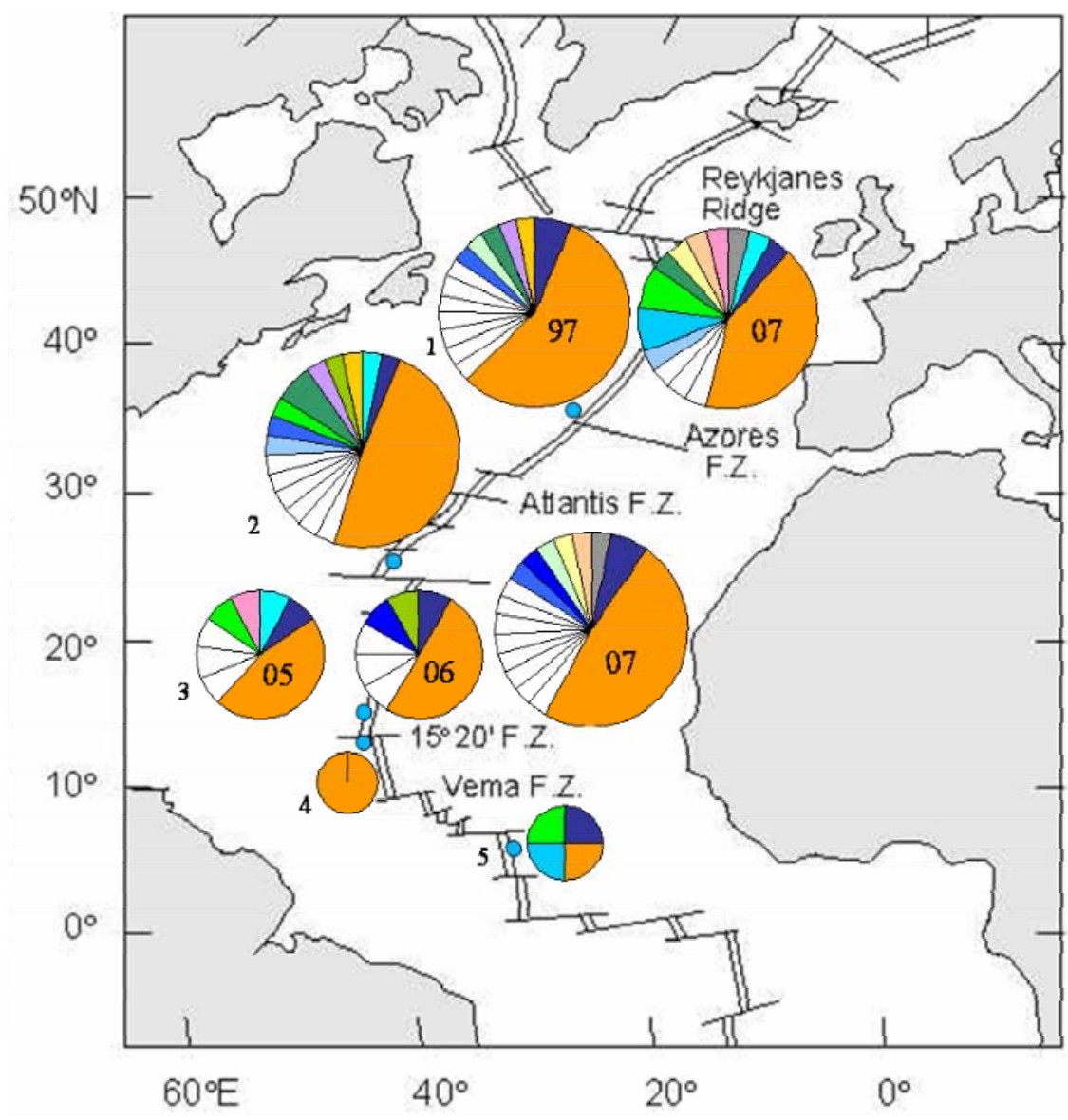

a)

\section{Rainbow 1997 and 2007}

2. TAG

3. Logatchev 2005, 2006 and 2007

4. Ashadzé

5. South MAR b)

\begin{tabular}{|l|l}
\hline & Hap. 3 \\
\hline & Hap. 4 \\
\hline & Hap. 5 \\
\hline & Hap. 6 \\
\hline & Hap. 11 \\
\hline & Hap. 13 \\
\hline & Hap. 15 \\
\hline Hap. 19 \\
\hline Hap. 25 \\
\hline Hap. 26 \\
\hline Hap. 28 \\
\hline Hap. 29 \\
\hline Hap. 30 \\
\hline Hap. 31 \\
\hline Hap. 32 \\
\hline Hap. 37 \\
\hline Hap. 39 \\
\hline Singletons
\end{tabular}


Figure 2. Haplotype network of the obtained mtDNA haplotypes of Rimicaris exoculata sampled along the Mid-Atlantic Ridge. Each circle represents a different haplotype, with the size of each circle proportional to the number of individuals displaying that particular haplotype. The white circles represent singletons (haplotypes that occur only once, represented by a single individual), the haplotypes found in more than one individual are identified and represented by pie charts, the colours used represent the locations where that haplotype was found. Segment size is proportional to the relative frequency of a haplotype in each population where it is present. a) Colour key to the locations where each haplotype was present.

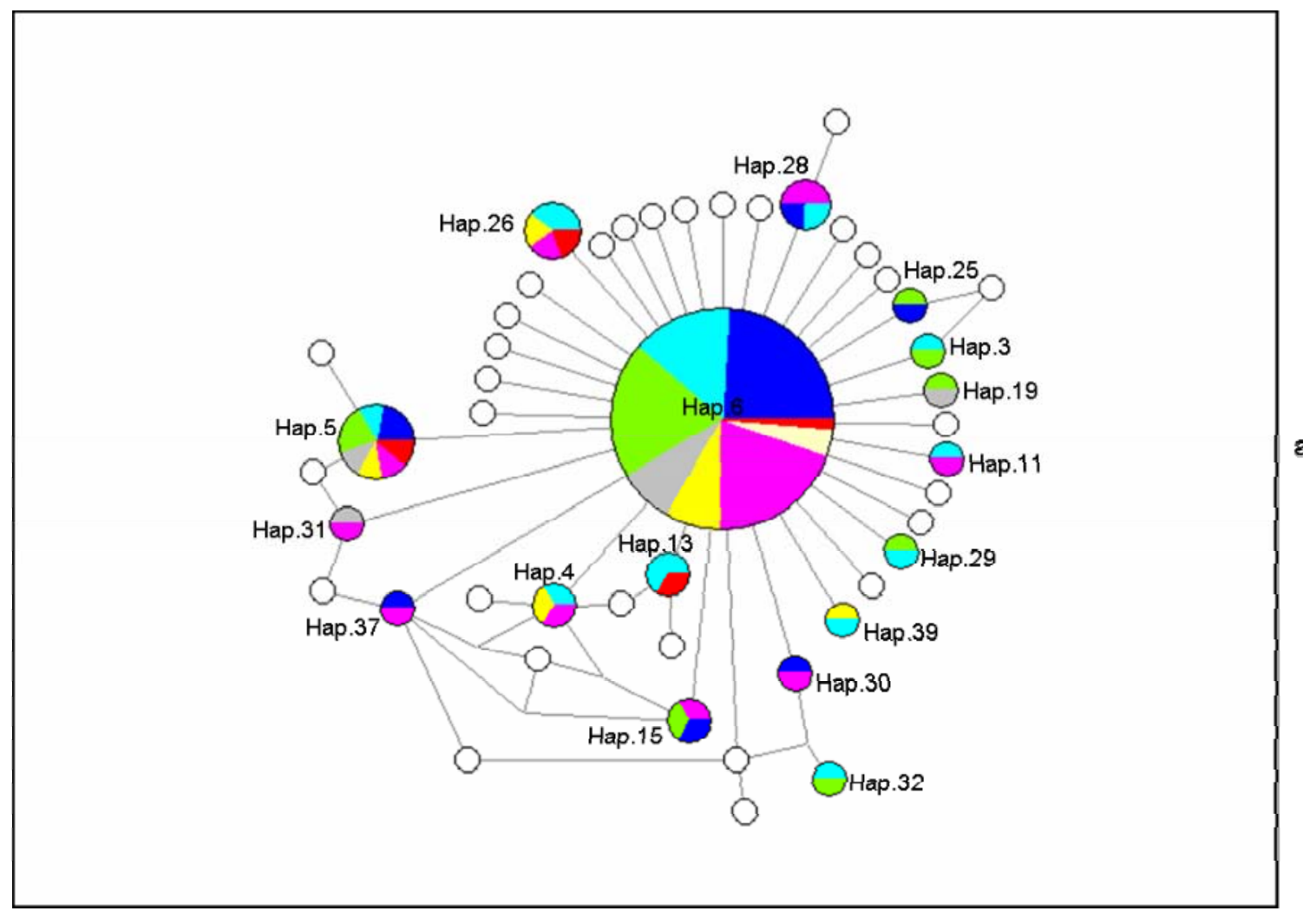

a)

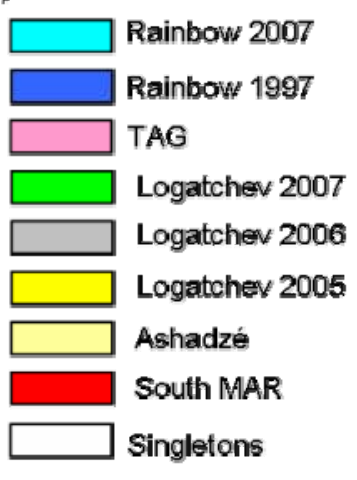


Figure 3. Mismatch distribution of nucleotide pairwise differences for all the mitochondrial COI sequences analysed (152) for Rimicaris exoculata sampled along the Mid-Atlantic Ridge.

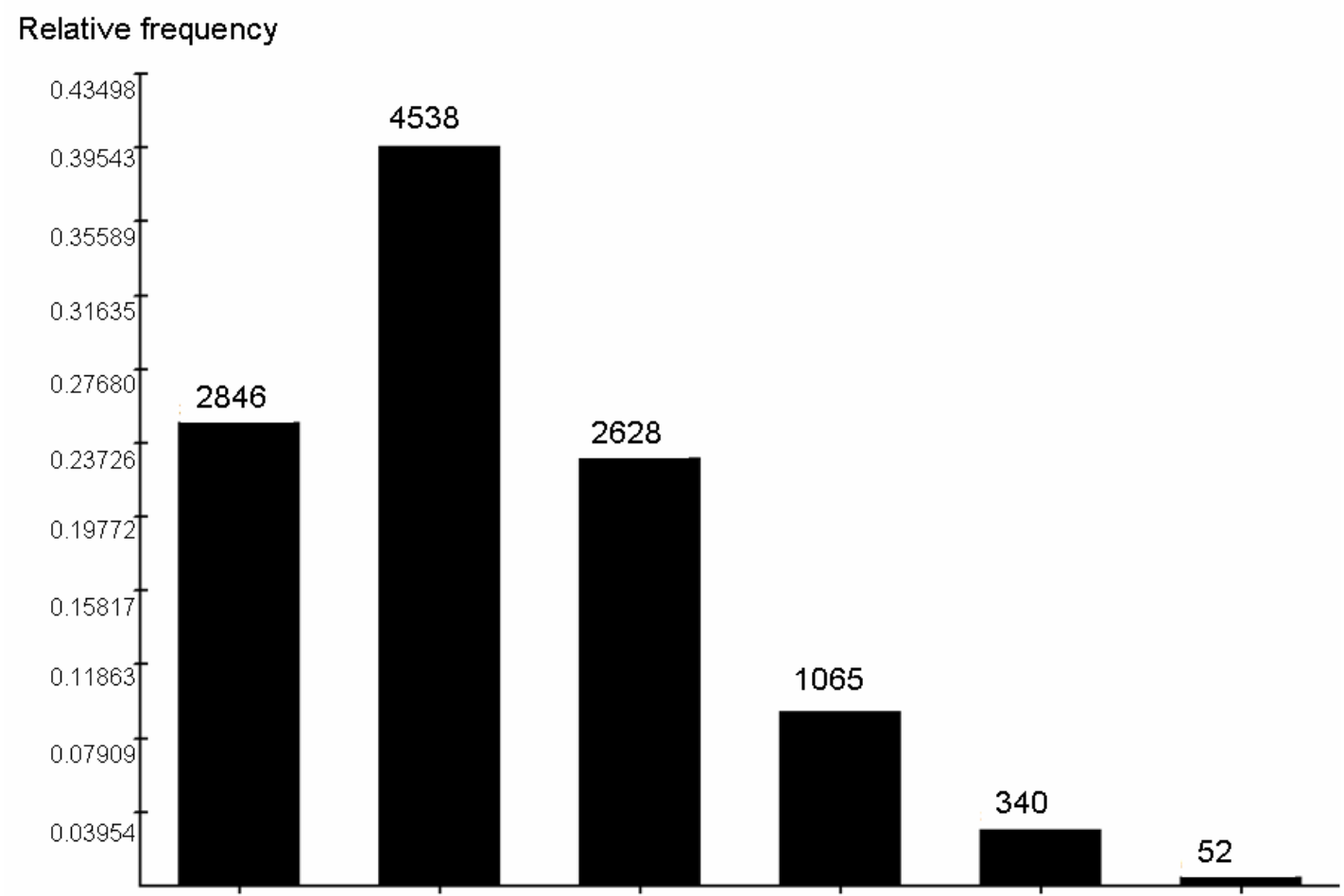

Unweighted mean pairwise difference: 1.277 
Figure 4. Observed and simulated mismatch curves of nucleotide pairwise differences of mitochondrial COI sequences of Rimicaris exoculata sampled along the Mid-Atlantic Ridge. The graphs represent a comparison of the observed curve of nucleotide pairwise differences to (a) a simulated curve assuming constant population size and (b) to a simulated curve assuming a population growth/decline model.

a)

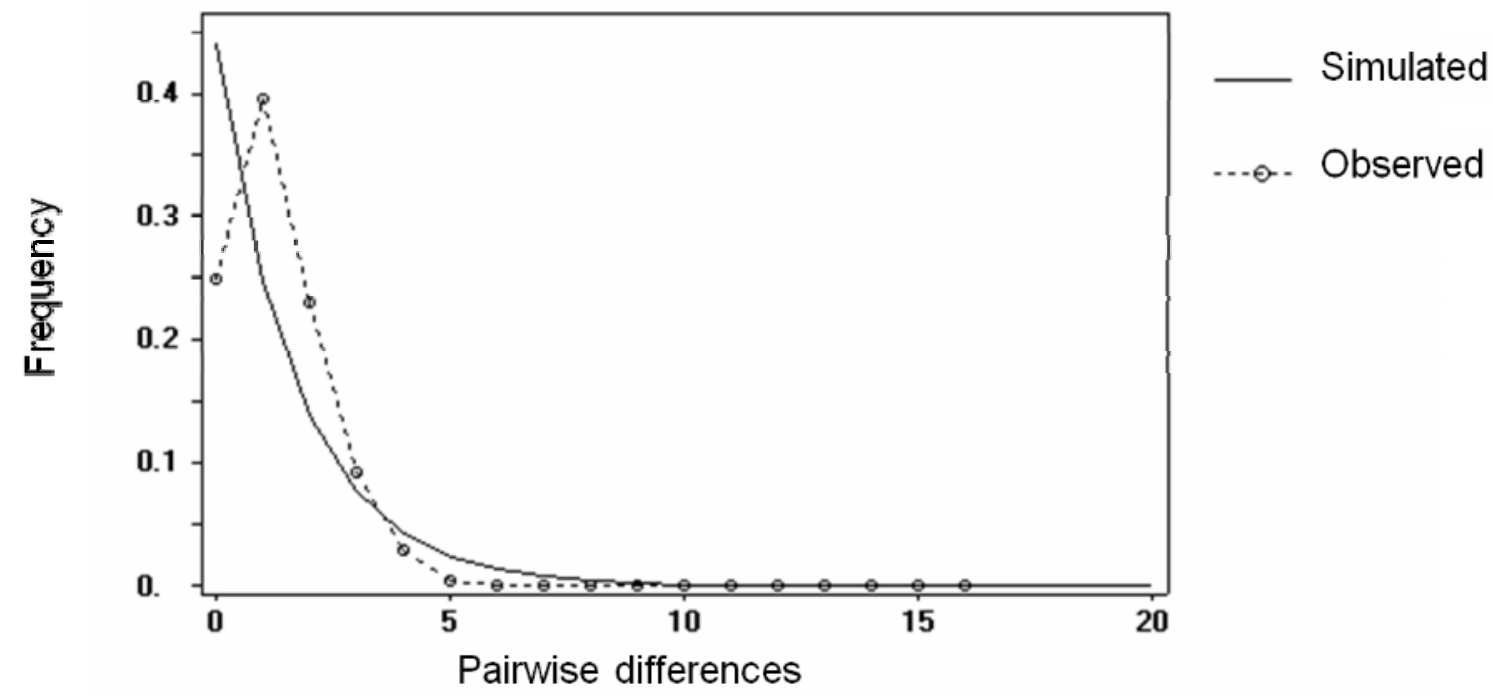

b)

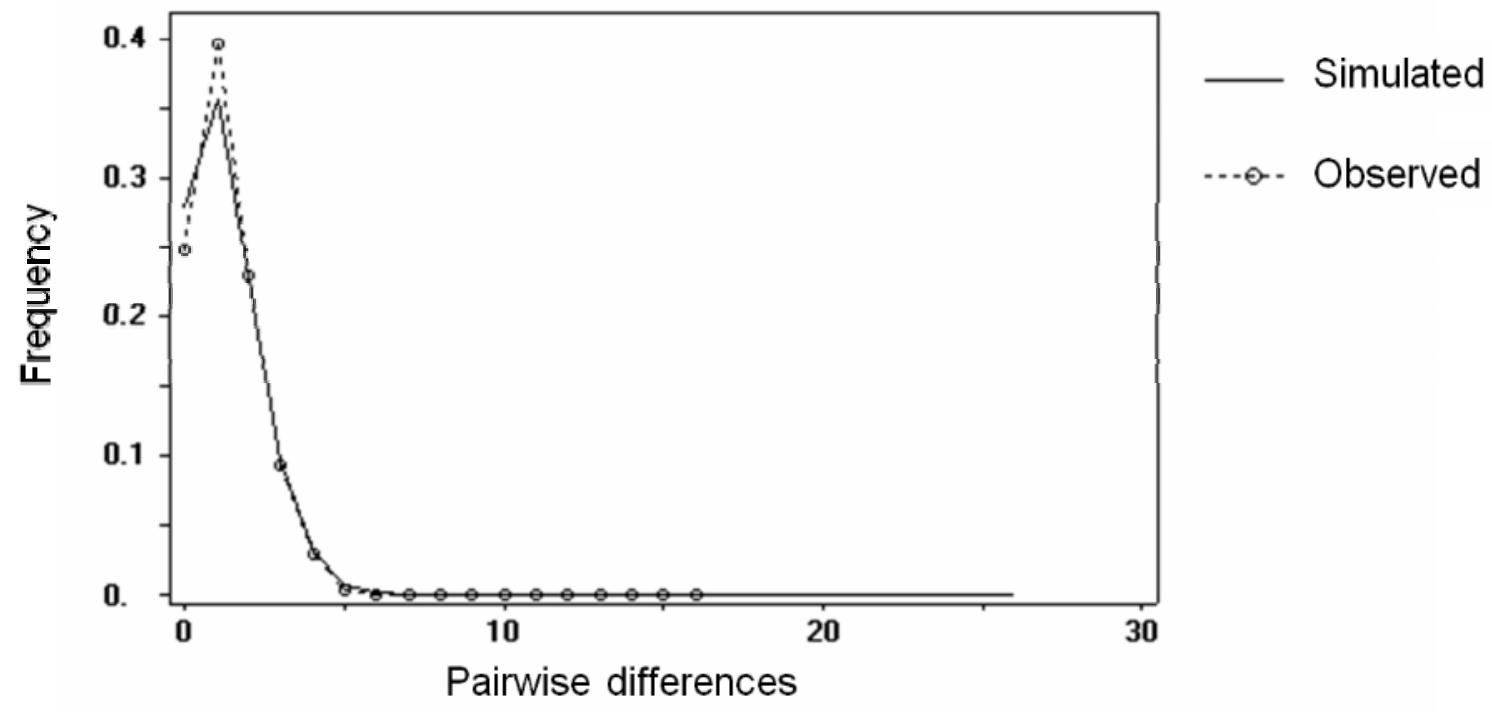

\section{Supporting information}

Fig. S1. Neighbour-joining phylogram constructed under the HKY mutation model with 152 COI mitochondrial sequences of Rimicaris exoculata. The outgroup used was the bresiliid shrimp Alvinocaris sp. All bootstrap values are shown. a) Colour key to the geographic location where the sequences were present. 


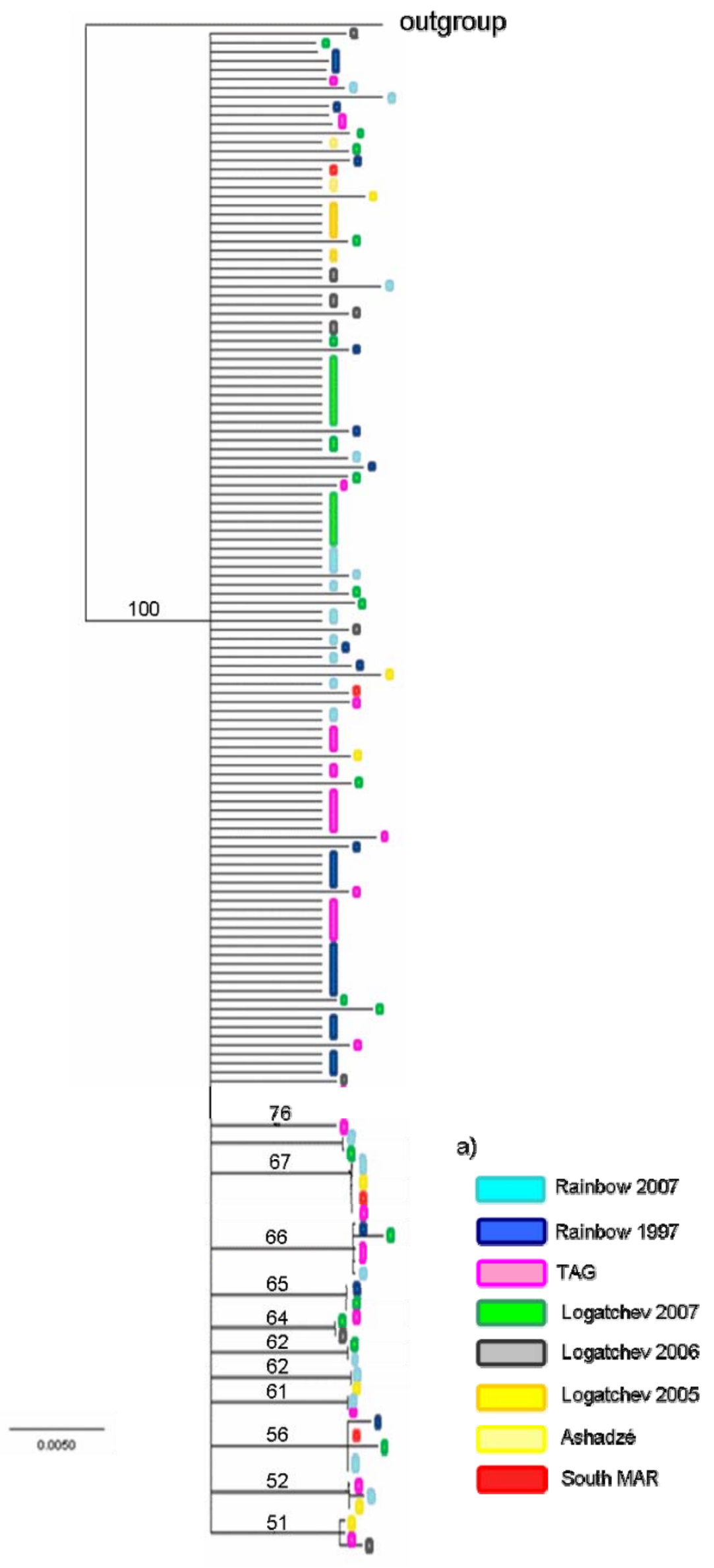

